\title{
To Be Marketed
}

National Cancer Institute

\section{Source}

National Cancer Institute. To Be Marketed. NCI Thesaurus. Code C101711.

Indicates that a product is intended to be promoted for use at a future time. 